\title{
The Nature of Language and the Problem of Language Planning
}

\author{
Tatiana Leshkevich \\ Southern Federal University \\ Rostov-on-Don, Russia \\ E-mail: Leshkevicht@mail.ru
}

\begin{abstract}
The article considers the nature of the language in conjunction with the problem of language planning. The purpose of the article is to identify the specifics of the language planning process in the modern digital era, based on the understanding of the language as a system of signs. The author analyzes the following three aspects. First, the article raises a question about the nature of a language and shows that the language is a tool for social coding, providing the transmission of human experience. Second, the author defines the key part of the problem of language planning generated by the fact that language is largely congruent to sociocultural type of the social system. Third, the attention is paid to the factors determining process of language planning. The theoretical basis of the research includes the works by contemporary scholars: Kaplan B., Richard B., Baldauf Jr.; Nahir, Moshe; Wardhaugh, Ronald; Ferguson, Gibson, aimed at studying the phenomenon of language planning, as well as the fundamental conclusions of K. Marx and F. Saussure. Methodological strategy of studying the problem of language planning relies on a set of methods and approaches, among them the system-structural method, the method of description and observation, the method of interpretation and the linguistic experiment. This research highlights the importance of the dialectical relation between form and meaning, the principles of unity and diversity, historicism and development. As a result, the author comes to the following conclusions. The language planning should conform to three principles: efficiency, adequacy, and acceptability. Globalization and digitalization determine language planning anonymously. The high level of social mobility and large-scale migration are the additional factors intensifying language planning. The author is confident that the elites play a leading role in the course of language planning due to the fact that the language is a means of the control, management and manipulation. Finally, results of language planning are spread through the education system and the mass media.
\end{abstract}

Keywords—language; sign; sociality; language planning; globalization

\section{INTRODUCTION}

Language is a multifaceted phenomenon, it is learned by many disciplines. Linguistics, logic, anthropology, psychology, semiotics offer the conclusions and achievements for generalization in the philosophical theory. The language performs many functions, including the storage, processing and transmission of information and human knowledge. Human communication would be impossible without language. It can be said that language acts as a "practical consciousness," because the thinking of a person objectifies itself in language.

The modern linguistic picture of the world reflects the priorities of the epoch, the principles and norms of the particular social groups, as well as the subjective needs and internal world of native speakers and creators of texts. The language seeks to preserve the world heritage, to formulate the priorities of human existence, accumulating the experience of being and the collective memory of humanity. The language gives to the phenomena their meaning and a certain direction. Such functions of language as estimation, abstraction, ordering and sequencing constitute the sphere of spiritual transformation, which is necessary for human communication and interaction. Freshness, originality, unpredictability and wealth of the language can be characteristic of it as well as poverty, and primitiveness. For a long time, it was believed that the main task was "not to prescribe language laws, but to describe them." Today the Internet language is a special problem of our time, due to the fact that huge masses of Internet users are involved in the Internet communication space [1]. The innovations of modern sociocultural reality should be adequately reflected in the language planning. Thus, the problem of language planning is of particular relevance. The real process of language planning should always take into account the interrelation of the principles of exteriorization and internalization. In other words, the success of the language planning process is determined by both external circumstances and internal personal attitudes. They enable researchers to identify contemporary individual communication and educational needs.

\section{ThE WAY to Understand the NATURE OF LANGUAGE}

In order to consider the relationship between language and thinking, it is necessary to first examine the nature of language. First of all, it should be emphasized that social reality is a field of interacting individuals, which are characterized by two types of communication. The first type is synchronous targeted communication as a means of coordinating human activities. The second type is the diachronic communication for the transfer of knowledge 
from generation to generation. The differences between these two types of communication are very significant. However, both types of communication use the sight, and the language acts as "iconic reality" that is necessary for functioning of society. Thus, the language should be understood as a system of signs providing interaction of people.

This is perhaps fairly well-known characteristic, but it should be noted that the language is a specific means of storing and transmitting information, as well as an instrument for managing human behavior. In other words, language can serve for designation, storage and transfer of human knowledge, only, if it is a system of signs or sign reality. The world of external objects and processes is represented by means of the language as a universe of symbolic models.

In search of evidence that the specific nature of language is expressed precisely by a system of signs, let us pay attention to the following circumstances. The sociality, with manifests itself as people's relations concerning things and the attitude of people towards people, is not assimilated by genes and is not inherited. Without a doubt, the insufficiency of biological coding is the main argument that promotes an understanding of the nature of language as a sign reality. Man as a social being is forced to use quasibiological remedies of reproducing sociality for the coming generations. A sign is a kind of "hereditary" instrument of social coding, ensuring the preservation and translation of human experience, which is necessary for society. At the same time it is necessary to accent that the sign can't be transferred by the bio code as a means of hereditary biological coding [2].

The system of the signs that forms the human language is in many respects the achievement of social, but not evolutionary development. Thus, it is correct to conclude that language is a social phenomenon, reflecting collective norms and requirements. New terms and concepts cannot be constructed on the basis of one's "own will" alone. It can be said that language is not invented by anyone, it arises and is formalized together with sociality, the human collective. In this connection, the following conclusion of $\mathrm{K}$. Marx is very realistic: "neither thoughts nor language in themselves form a realm of their own, they are only manifestations of actual life" [3]. Language acts as a necessary link between practice and consciousness. As a sign reality, it fixes information about those connections and dependencies that have become invariants of objective activity.

\section{LANGUAgE PlanNING Problem}

As we know, the notion that language is a social phenomenon has become widespread. It is necessary to agree that similar views have been developed within materialistic philosophy and characterized specific approach of K. Marx. Over time they have gained the significance of common truth. However in the present period one can observe that most modern scholars reveal and identify the phenomenon of "language planning" [4]. It is believed that language planning is a reasonable way out of the current situation [5].
According to researchers, the language is aimed at reflecting the standards, priorities and orientations of the era [6]. It is assumed that the modern language is congruent with the sociocultural type of the social system in many respects. By means of language occurs both the fixing and mastering of existing norms and values, as well as the formation of new preferences, which correspond to their time. The global world and the digital era dictate their priorities, which in turn generate new language constructs, new terms and concepts. Globalization is the mega-trend of the modern life [7]. Language manifests the relation of human consciousness to reality and promotes the objectification of norms, rules and restrictions, developed by society. In connection with changing needs and socio-economic conditions, it demonstrates such characteristics as dynamism and selectivity.

However, the problem arises: can the language be planned? Who is the initiator of this language planning process? In our opinion, it seems possible to suggest three versions of the answer to this question. First, presumably, one can point to the process of globalization and digitalization, which anonymously implement language changes. Globalization is spreading its influence across borders of countries and continents covering economy, industry and technology as well as culture, social ideas, art and lifestyle. The language undergoes modifications under the influence of specific scientific, technical, socioeconomic process and practical needs. Today, the pattern of daily life includes the innovations generated by globalization as a certain value. However, the main tendency of globalization is unification or standardization suppressing a variety of traditions. It can be said metaphorically that "national cultures are overflowed and washed away by the waves of globalization". Globalization imposes the stereotypes of consumption and mass culture.

Secondly, in opposition to the previous idea, it is logical to assume that a group of political leaders and elites could become a leading group of effective language planning, due to the fact that language is a tool of control, management and manipulation. Thirdly, it must be kept in mind that the high level of social mobility, as well as intensive migration dynamics is also the powerful reason for language planning. It should be recalled that migration is considered the main and most complex problem of the 21 st century. Today migrants make more than $3 \%$ of the population that is equal to 200 million people. Therefore, the impact of migration on the language is a very real process, which produces significant changes in the contemporary linguistic picture of the world. Based on the fact that ghettos and linguistic enclaves are formed, there are even assumptions of peculiar "parallel society". At a minimum, large-scale migration flows provoke situations when the population becomes bilingual. At the same time, the problem of language presence requires its particular solution in each special case in order that people haven't been excluded from professional and social life. As a rule, the first step in solving the language problem is to study the languages of the host countries. 
However, despite the fact that changes in the linguistic picture of the world under the influence of migration flows are obvious, scientific research pays not enough attention to this issue. Apparently, it should recognized that the impact of migration on language change is not at the heart of the debate. Meanwhile, the mission of language to promote the cross-cultural mutual understanding based on universal human values.

Generally, the language planning focuses on the comprehension and frequent use of new terms and glossary to describe innovative processes, phenomena and inventions that are being introduced into the social life and the world of lived experience of contemporaries. As a rule, the results of language planning have a chance to spread and circulate in community through the education system and mass communication [8].

\section{MethodologicAl Strategy OF THE RESEARCH}

The study of the phenomenon of language and the problem of language planning relies on a number of methodological principles, approaches and methods. Since a language is a certain system that has a structural organization, in this case the systemic and structural approaches are the main methodological means of studying its dynamics. It should be noted that the understanding of the language as a system has come quite late, only in the 20th century the systemic approach became the most important methodological principle of linguistics. The structural approach has been recognized through the scientific work of F. Saussure [9]. Apparently, it is necessary to remind that the structural approach is also called taxonomic. The structural approach has shown that expressions of the language have some general structural features which demand classification.

It should also be stressed that the development of a language is a holistic phenomenon. Therefore, the principle of integrity serves as a basic methodological framework. The description method, which had as its goal the description of linguistic facts, has always been considered a general linguistic method. Its advantages include the fact that this method is aimed at the description of real linguistic phenomena, which are analyzed in a certain historical perspective. As a rule, the description method is accompanied by observation techniques. In this case, the method of comparative analysis is used as an important and necessary methodological tool.

If we shift the focus of attention to the deep structure of language, we can see the distinction between sign and meaning, language and speech, social and individual. The dialectical relation between form and meaning, the principles of unity and diversity, historicism and development appear to be significant for studying configurations of language. Therefore, the dialectical method, which points to the contradictions of the development process, is not devoid of significance in the analysis of language. The person is able to change a situation by transferring it from one semantic form to another. The transformations produced by the language are carried out in the semantic field, and this allows a person to create the desired image of reality, to simulate events and patterns of behavior, to identify personal life values. The language makes it possible to test and evaluate various situations. However, the difficulties arise on this way. The main one is related to the contextual dependence of language. As scientists emphasize: "pragmatics studies the use of language in context, and the context-dependence of various aspects of linguistic interpretation. One branch of pragmatics investigates how context determines a meaning for a sentence..." [10]. Proceeding from this position, there is obvious a special role of a method of interpretation. The method of interpretation is aimed at expressing the subjective perception of events and the individual attitude to living conditions.

Presumably, the method of linguistic experiment is effective in the study of innovative transformations of the modern language. The linguistic experiment and statistical observations show how often new linguistic constructions and terms are used and how deeply they will be rooted. According to our position, the emergence of innovations in the language is a response to the challenges of modern technological development of society. Language planning is aimed at solving problems of contact with the masses and the formation of channels of modern communication. In general, the methodology of language planning has to correspond to three principles: efficiency, adequacy and acceptability.

\section{CONCLUSION}

The main conclusions of the study consist in the following. Firstly, in the broadest sense, the language should be understood as a system of signs that provides storage and transmission of information, human communication and control of human behavior. As a system of signs, language frees a person from having to keep everything in memory, forming the necessary link between practice and consciousness. Secondly, in the modern period, the problem of language planning is of particular significance and relevance. The problem of language planning is focused on the awareness and frequency of using new terms and a glossary describing innovative processes and inventions that need to be incorporated into social life.

Thirdly, the global world and the digital era dictate their priorities, which in turn generate a new language design, new terms and concepts. Numerous language innovations appear as a result of intensive technological development and they are aimed at creating modern communication links. Therefore, digitalization and globalization can be evaluated as the anonymous factors causing significant changes of language. It should also be emphasized that the active leading social group for effective language planning is a group of political leaders and elites. It presumably is explained by the fact that language is a means of control, managements and manipulations. The high level of social mobility and the intensive dynamics of migration are also the powerful reason for language planning.

Fourth, it is assumed that the method of linguistic experiment is an effective tool in the research of innovative transformations of the modern language. It seems to us that language planning is not limited to the protection of 
uniformity or to the hybridization of language. The linguistic experiment and statistical observations show how deeply new language constructs and terms have taken root, how often they are used. In general, the language planning process has to correspond to three principles: efficiency, adequacy and acceptability. The results of language planning get chance to spread and circulate in society through the education system and the mass media.

\section{REFERENCES}

[1] T.G. Leshkevich. Communicative practices in their semantic orientation on algorithms of successful interactions//Proceedings of 4th International Conference on Education, Language, Art and Intercultural Communication (ICELAIC 2017). Paris: Atlantis Press, 2017. Vol. 142, pp. 374-377.

[2] T.G. Leshkevich, "Language as a sign reality; horizons and metamorphoses ", Problems of language in the global world, M: Publishing house Prospekt, 2016, pp.101-111.

[3] K. Marx, F. Engels, Selected Works, vol. 3. M., 1985, P. 449.

[4] R. B. Kaplan, R. B. Baldauf, Language Planning from Practice to Theory. Clevedon: Multilingual Matters Itd., 1997, P. 404.

[5] Wardhaugh, Ronald. "Planning," in An Introduction to Sociolinguistics. Malden: Blackwell Publishing, 2008.

[6] Nahir, Moshe. Language Planning Goals: A Classification.//Sociolinguistics: The Essential Readings. Eds. Paulston, Christina Bratt and G. Richard Tucker. Oxford: Blackwell, 2003.

[7] O.V. Chistyakova, "Self and other in the communicative space of the global world" in Proceedings of the 2017 2rd International Conference on Contemporary Education, Social Sciences and Humanities, 2017, pp. 6-11.

[8] Ferguson, Gibson, Language Planning and Education. Edinburgh University Press. 2006, P. 243.

[9] F. de Saussure, Works on Linguistics, M., Progress, 1977.

[10] Philosophy of language//The Cambridge Dictionary of Philosophy General Editor Robert Audi. Cambridge University Press, 1995, pp 586-589. 